\title{
GEOPHYSICAL CHARACTERIZATION OF ALBIAN CARBONATES RESERVOIRS IN BRAZILIAN BASINS: THE SWEETNESS AS A TOOL FOR CARBONATE RESERVOIRS DEFINITION
}

\author{
Maria Gabriela Castillo Vincentelli ${ }^{1}$, Sergio Antonio Caceres Contreras ${ }^{1}$ and Michelle Uchoa Chaves ${ }^{2}$
}

\begin{abstract}
The current research is based on volumetric seismic interpretation with the aim to visualize the main Albian carbonate reservoirs in shallow, deep and ultra-deep water of the continental Brazilian basins (Santos, Campos and Espírito Santo). It is expected that the method assists geoscientists in order to define carbonate reservoirs with less geological uncertainty, when compared with the response obtained from the traditional seismic interpretation. The objective proposes a quickly, but confident, methodology to better define Albian carbonates using seismic attribute extraction. To achieve this goal, 25 seismic volumetric and surface attributes were analyzed; it was observed that it is possible to visualize the reservoir in most of them, mainly when the acoustic impedance (Al) is included on the analysis. For all the considered oil fields the sweetness attribute presented the best carbonate reservoir visualization and using sweetness any previous seismic interpretation is necessary. In conclusion, the sweetness attribute allowed the interpretation of the Albian carbonates reservoirs in the Brazilian basins in a short period of time and with less geometrical uncertainty. Due to this fact, is possible to enforce that the method can be applied for seismic characterization of any geological feature that shows changes in its density in comparison with the surrounding stratigraphic layers.
\end{abstract}

Keywords: volumetric interpretation, instantaneous frequency, instantaneous amplitude, envelope, limestone reservoirs.

RESUMO. A presente pesquisa é baseada na interpretação sísmica volumétrica com o intuito de visualizar os principais reservatórios de hidrocarboneto do Albiano em águas rasas, profundas e ultraprofundas das bacias da margem continental brasileira (Santos, Campos e Espírito Santo). É esperado que o resultado auxilie geocientistas na definição de reservatórios carbonáticos com menor incerteza geológica, quando comparado com a resposta obtida numa interpretação sísmica tradicional. 0 objetivo propõe um método rápido e confiável que melhor defina os reservatórios carbonáticos do Albiano por meio da extração de atributos sísmicos. Para alcançar esta meta, 25 atributos sísmicos volumétricos e de superfície foram analisados, na maioria deles é possível visualizar o reservatório, principalmente quando a impedância acústica (Al) é incluída na análise. Para todos os campos de hidrocarboneto avaliados o atributo sweetness apresentou a melhor visualização do reservatório carbonático, sendo que para aplicar sweetness não é necessária uma interpretação sísmica prévia. Em conclusão, o sweetness permitiu a interpretação de reservatórios carbonáticos albianos nas bacias brasileiras em um curto período de tempo e com menor incerteza geométrica da distribuição do mesmo. Devido a isso, o método pode ser aplicado para a caracterização sísmica de feições geológicas que apresentem mudanças em sua densidade em relação às camadas estratigráficas ao redor.

Palavras-chave: interpretação volumétrica, frequência instantânea, amplitude instantânea, envelope, reservatórios carbonáticos.

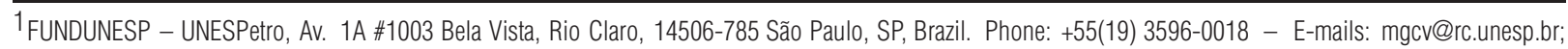
sacc@rc.unesp.br

${ }^{2}$ Schlumberger, SIS Norway Technology Center, Aslakveien 14E, Oslo, Akershus N0753, Norway. Phone: +55(47) 2160-9667 - E-mail: mchaves@slb.com
} 


\section{INTRODUCTION}

The Albian carbonate reservoirs are good oil producers in many Brazilian basins along the continental margin. Most of these oil fields were discovered at least 40 years ago and today, it is observed a low oil production from them. The reason for this could be divided in two factors: the main reservoir is depleted or the carbonate system is not well known, until now.

The main objective of this study is to present a methodology which enables a quick visualization of these carbonates reservoirs with a high confidence on the interpretation.

In this sense, 25 seismic attributes surface and volumetric attributes were tested, and the sweetness showed high quality and efficiency in the visualization of the main Albian oil field in Campos, Santos and Espírito Santo basins. The advantage of use sweetness is related to the period of time that the interpreter needs to illuminate the reservoir, because it is not necessary previous seismic interpretation; the way is to calculate sweetness, and after applying opacity and transparence on the attribute volume (box probe) at the reservoir depth.

On this workflow, the attribute was tested in shallow, deep and ultra-deep water depth and also in exploratory areas, getting a good extraction of the reservoir amplitude.

The main stratigraphic interval evaluated here is the Albian reservoir, that in Campos basin is recognized as Macaé Formation. The equivalent analyzed reservoirs for Santos and Espírito Santo basins are Regência and Guarujá formations respectively. In general, its geological description is defined as limestone (oncoolite/oolite) locally dolomitized. The goal of the project was to characterize the calcarenites (reservoirs) with porosities varying from $15 \%$ to $21 \%$ and average permeability of $250 \mathrm{md}$.

The motivation to test volumetric attributes is related to the poor visualization of the carbonates reservoirs in the available seismic data, which reflects a low seismic resolution (low frequencies) where the main reservoir is missing in the velocity model (Fig. 1). As a consequence, an inversion model will reflect only the low frequencies, in other words, it will not be able to solve the problem of a realistic visualization of the main reservoir.

Sweetness is not a new attribute, but traditionally sweetness was applied to visualize sands bodies from the shale background. Hart (2008) applied sweetness joint coherence attribute in order to detect sand channels in 3D seismic data, and it was concluded that sweetness is less efficient when the acoustic impedance contrasts between sands and shales are low. On this hand, if we think that the contrast between siliciclastic and carbonates generates high acoustic impedance contrast, it would be possible to highlight the carbonate reservoir. In addition, the main Hart's suggestion is to calibrate the lithology identified by the attribute using well logs.

\section{OBJECTIVES}

The objective is to perform a seismic visualization and characterization of the limestone reservoirs, based on its geometrical distribution, using a seismic attribute extraction methodology. The intention is to recognize calcarenites reservoirs into calcareous matrix.

In addition, this method will reduce the uncertainty related to the definition of limestone's reservoir distribution in volumetric seismic interpretation.

\section{GEOPHYSICAL PROBLEM DEFINITION}

The main problem is related to the energy recovery for carbonates reservoir (CR) levels, in this case the energy is capture by the high velocity layer (CR) and its reflected wave is weaker than the overlying stratigraphic layers. This physical condition is associated to traditional seismic surveys where only the compressional wave $(P)$ is recorded, therefore most of the seismic surveys available for Brazilian exploration involve this type of acquisition. The reason of the previous fact is that the another alternative: the multicomponent seismic acquisition, where the $\mathrm{P}$ and $\mathrm{S}$ - shear waves are recorded, is expensive for exploratory purposes, and because of this it is a tool restricted to some hydrocarbon oil fields with high hydrocarbon potential and commercial interest.

The reason why the seismic image in multicomponent acquisition is better than the traditional is because both $S$ and $P$ waves are recovered. However, the $S$ wave is usually splitted in two, a fast and a slow mode, and as a result of its own anisotropy, the seismic image and amplitude heterogeneities would be improved through the seismic processing.

The case of the seismic ray trajectory along basins with carbonates layering is illustrated on the Figure 2 . The green ray travels along the siliciclastic column, is reflected on the top of the carbonate reservoir and recorded on the surface giving information about the top of the carbonate reservoir. The refracted wave (red ray) travels through the Albian carbonate level. Part of this energy is reflected (red ray) and the other part is trapped inside the carbonate (dark blue ray). The reflected wave is recorded while the trapped one generates seismic noises that turn difficult the seismic interpretation in the carbonate reservoir.

Another fact is that the amount of recovered rays that comes from the internal configuration of the carbonate layers are lower than the signal recovered from siliciclastic layers. The last physical ray condition does not allow the recovery of the full energy, and as a consequence, the seismic image and the heterogeneities in amplitude distribution of the 3D volume are poorly visualized (Fig. 3). 


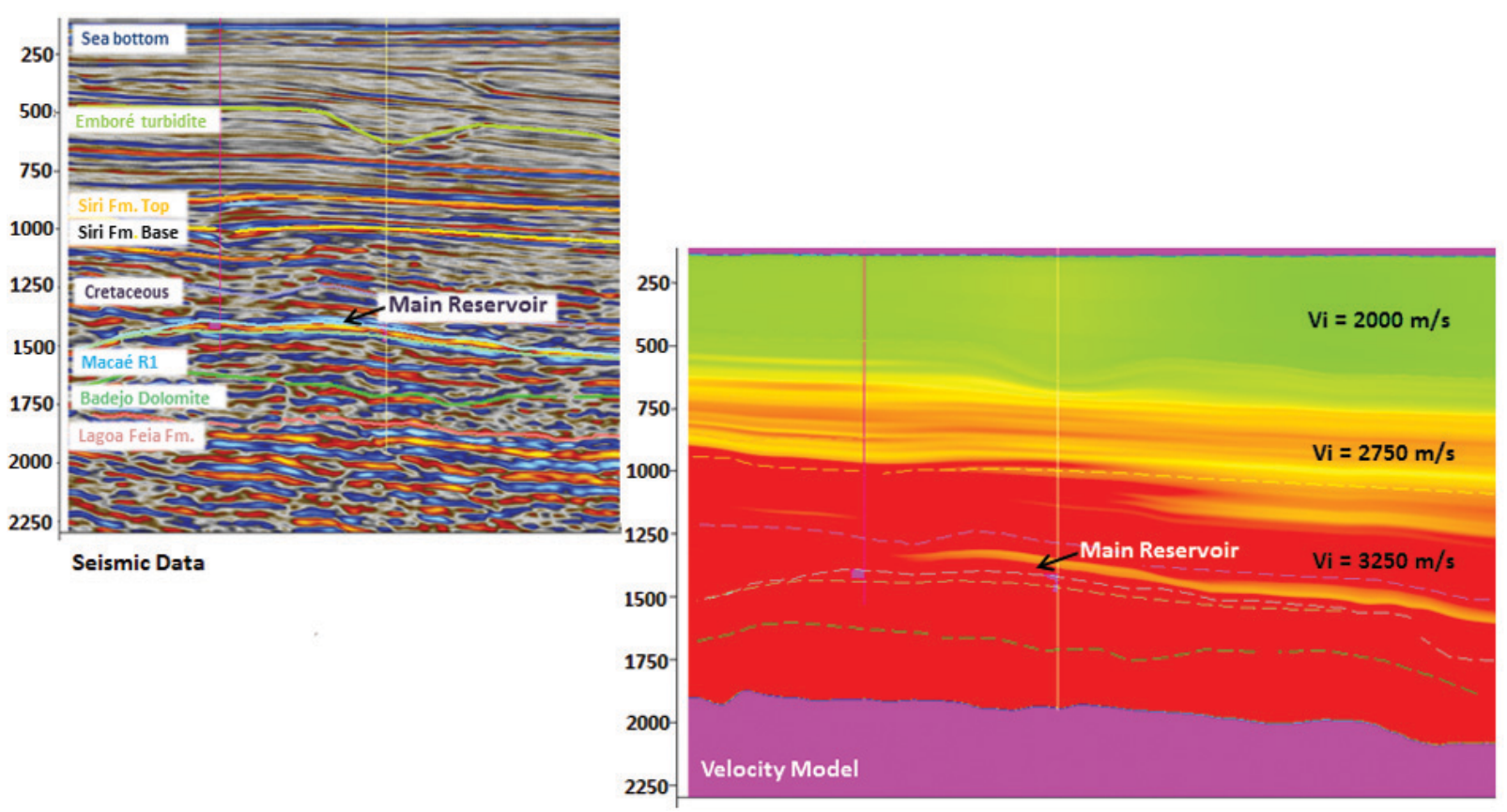

Figure 1 - Seismic line and velocity profile containing the main reservoir. Observe that the main carbonate reservoir is missing in the velocity model; the reservoir is indicated by the arrow in the seismic line and in the velocity profile.

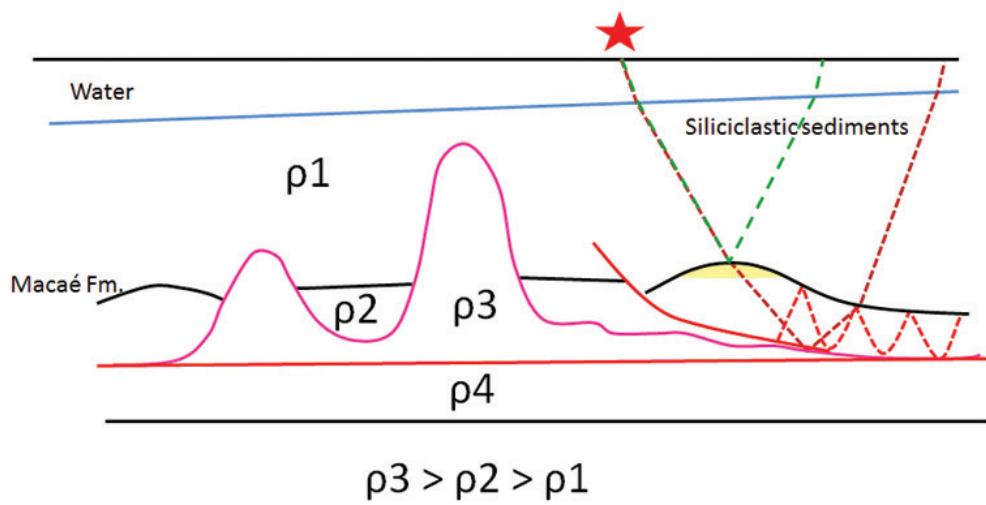

Figure 2 - Schematic diagram of the energy partition in carbonates environments: the wave generated in the point of the red star is propagated along the entire siliciclastic column and its generated reflected waves are recovery on the surface. When the wave penetrates the carbonate layer (black horizon - Macaé Fm.), the amount of the recovery energy of these rays are less than the signal recovered from the siliciclastic layers.

In order to better control the geological impact of carbonates layers in the seismic data quality, the sweetness attribute was analyzed and applied among others, presenting good results for visualization and interpretation of the carbonate reservoir.

\section{BUT, WHAT DOES SWEETNESS MEAN?}

Previous studies applied sweetness attribute as an empirical algorithm designed to identify oil and gas prone areas because its answer on seismic data revealed strong amplitudes and low frequencies (case of the Albian carbonates in Brazil).
Mathematically, sweetness is the ratio between envelope and the root square of the instantaneous frequency (1); in other words, it is able to identify features where the overall energy signature changes in the seismic data.

$$
\frac{\text { Sweetness }=\text { Envelope }}{\sqrt{\text { Instantaneous Freq. }}}
$$

When the envelope (instantaneous amplitude) is calculated, some geological considerations will be obtained from the analyzed seismic volume. These are related to the detection of the major lithological changes (e.g siliciclastic - carbonates inter- 


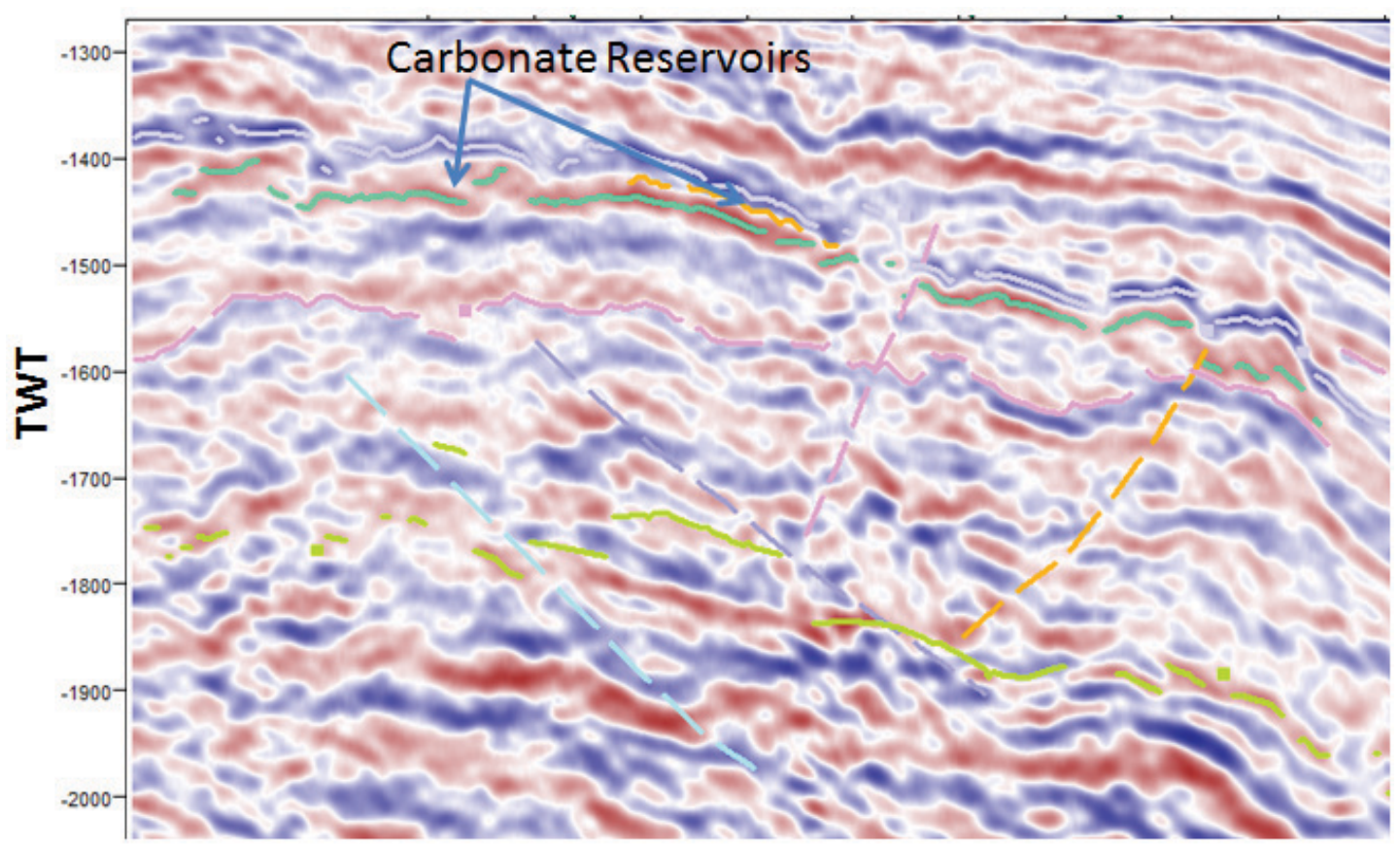

Figure 3 - Poor imaging of carbonates reservoirs showing low frequencies and strong amplitudes.

face). The result of this process is observed in Figure 4. If the lithologies in the GR profile (track 1: calcarenites in yellow and calcilutites in blue shown in Fig. 4) is compared with the wavelet trace extracted at the same point of the lithology data, it will be difficult to associate the amplitude changes with the changes in the stratigraphic column.

However, if the previous comparison is being done between the sweetness trace and the lithological changes, it is possible to recognize the point when the good porosity of the carbonate reservoir starts (1785 $\mathrm{m}$ ) as well as when it ends (e.g. the main carbonate reservoir that starts in $1795 \mathrm{~m}$ and ends in $1820 \mathrm{~m}$, with porosities varying from 13 to $28 \%$ ).

In the case where the shape of the envelope and instantaneous frequency is observed at the same track (track 6 in the Fig. 4), is possible to interpret that the main oil producer reservoir starts when the curve of Instantaneous Frequency cuts the envelope curve. Then, the reservoir containing hydrocarbon is defined by the areas in yellow when the value of the square of instantaneous frequency is higher than the envelope. The inverse relationship does not represent the potential hydrocarbon reservoir. An important consideration about the envelope is that the result does not depend of the seismic phase.

The Instantaneous Frequency (IF) attribute does not mean the frequency of the wavelet, and it is not a dependent function of the seismic phase. As defined by other authors and based on the trial and error of the attribute, the IF is useful in areas that show ciclicity of geological intervals most of them related to the 3th order cycles as defined by Vail et al. (1977), another sedimentary sequence characteristic verified here, being applied for the Brazilian Albian Carbonates (Fig. 5).

For Brazilian Albian reservoirs as well as others carbonatic reservoirs, the ciclicity is defined by the eustatic sea level changes, the energy of the carbonate environment and diagenetic process, this last mentioned, related to cycles of construction and destruction of porosities, because since the carbonate deposition diagenetic processes are working on the carbonatic bank. Due to these lower porosities observed at the base of the cycles identified on the neutron profile (Fig. 5), good porosities for oil accumulation could be preserved by fluid replacement or arisen after carbonate dissolution because the basin burial evolution. Along all the mentioned processes, a secondary porosity is formed, and in this case the total porosity will be different of the effective porosity. Finally, the carbonatic bank will be exposed and fresh water will open cavities that configure the maximum porosity on the reservoir. At the final stage, the cycle is ended by the reduction of the space for carbonate accumulation, shallower water depth and low porosities, also defining a kind of depositional ciclicity associated with the carbonatic bank.

As a result, when the IF is calculated, the reservoirs with hydrocarbon are highlighted as a maximum value in the resulted 


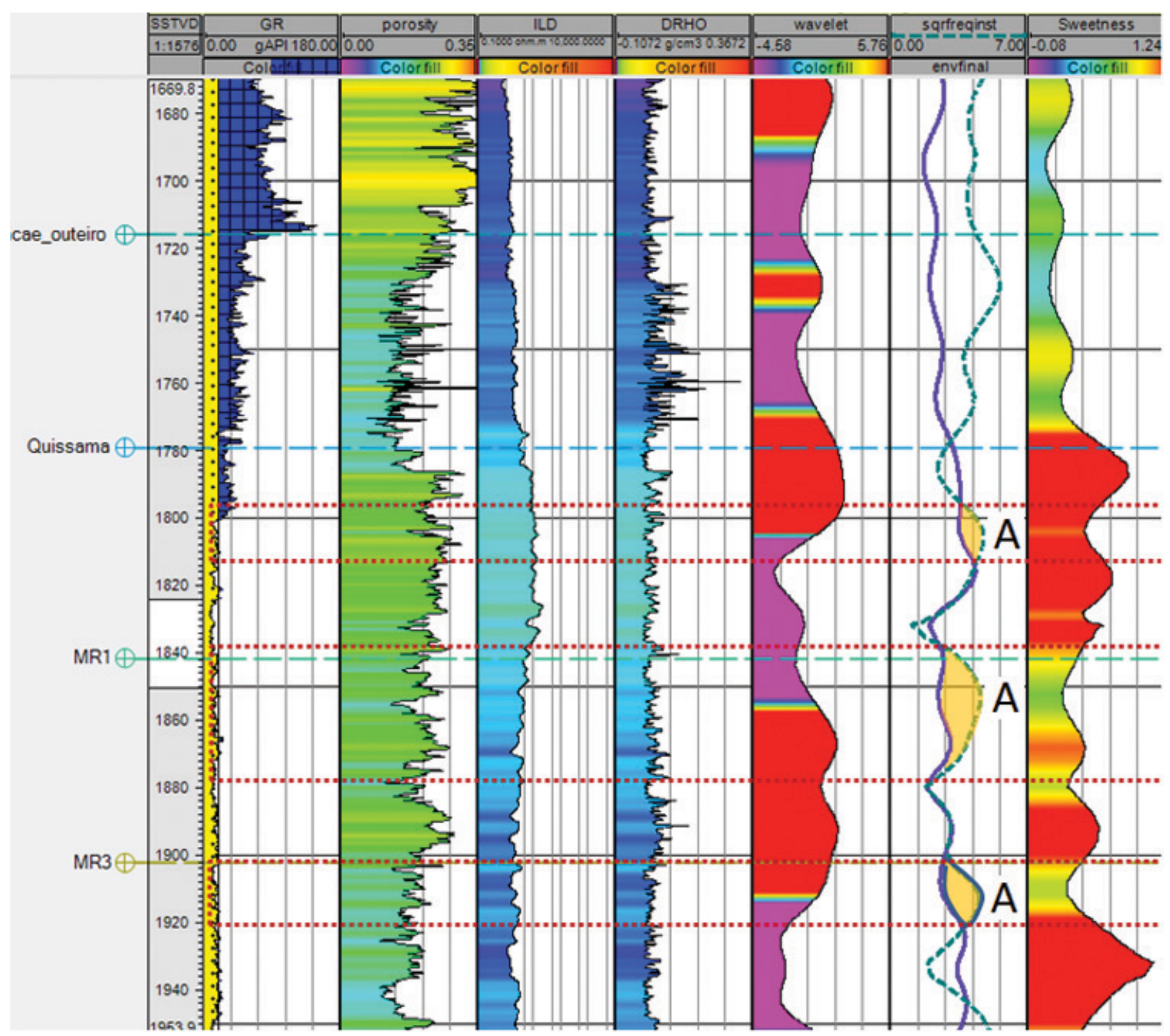

Figure 4 - Resulting profile of the sweetness process in the last track (track 7). In the previous track (track 6), the envelope and the root mean square of the instantaneous frequency were plotted at the same scale. Observe the main reservoirs highlighted in yellow and confirmed by the wells analysis. Track 5: extracted wavelet from seismic; Track 4: Density well log; Track 3: resistivity (ILD) log; Track 2: porosity profile calculated from the density log; Track 1: Gamma Ray well log with the interpreted lithologies, calcarenites in yellow and calcilutites in blue.

curve (letter A in the Fig. 4). This fact enables the interpreter to extract the reservoir on the IF attribute that allow the reservoir visualization and extraction from others stratigraphic layers that show similar density values (see the bulk density - RhoB profile values in the Fig. 5) by the identification of the top and base of the main reservoir, when integrated with the resulted curve of the envelope attribute. Therefore, the ratio between envelope and the root square of the IF highlights the carbonate reservoir.

One technical consideration must be done: If the signal/noise ratio is lower, the method will not give a low uncertainty results once IF is an unstable attribute in presence of noise.

\section{DATA AND METHODOLOGY}

The database is composed by small seismic cubes ( $50 \mathrm{~km}^{2}$ each), distributed along Santos, Campos and Espírito Santo basins. Most of them are located along well known oil-fields, in water depths varying from $100 \mathrm{~m}$ to $1800 \mathrm{~m}$. The adopted seismic data was acquired along 10 years of student's research projects in the LISG (Laboratory of Seismic and Geological data integration in UNESPetro - UNESP - SP), under the policy of the Brazilian National Petroleum Agency (ANP) that allows students from public Brazilian universities to acquire seismic and well data to develop academic research. 


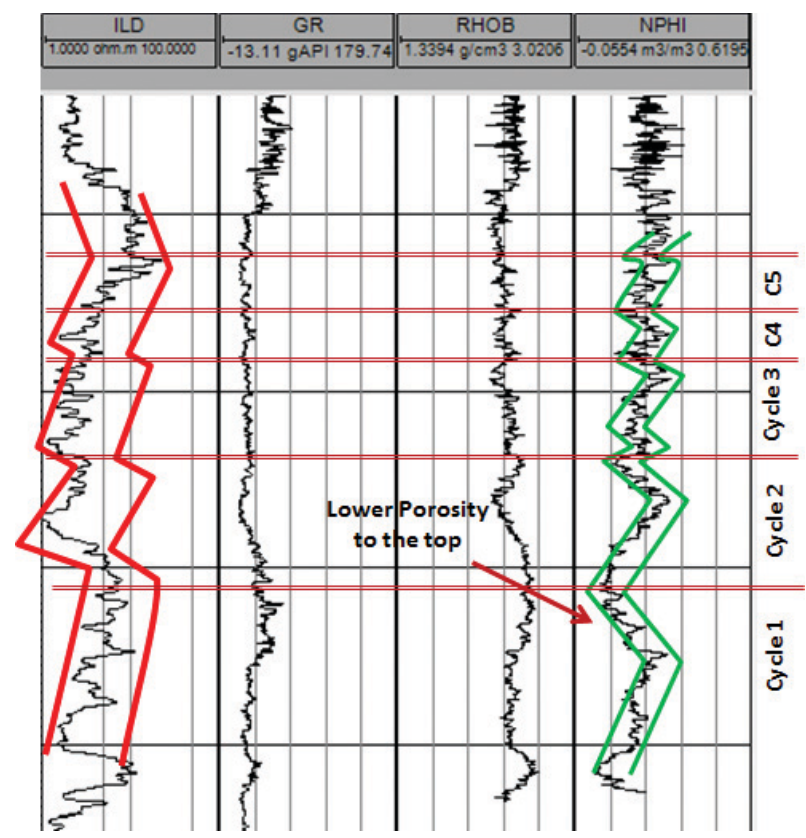

Figure $\mathbf{5}$ - At least five cycles of lower porosities can be recognized for offshore Brazilian Albian carbonates. Every cycle is limited by a top and a base.

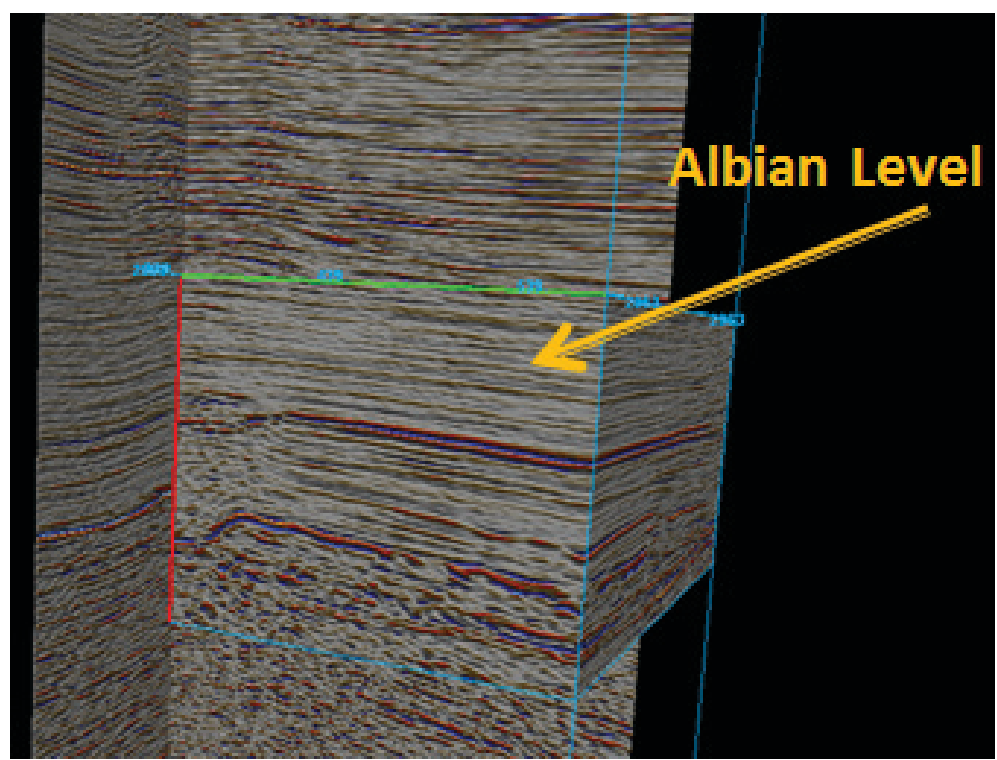

Figure $\mathbf{6}$ - Extraction of a cropped volume from the original amplitude cube in the Albian interval.

The methodology was based on the application of different volumetric and surface attributes in the original seismic cube (Fig. 6). At least 25 attributes, all of them related to stratigraphic features and signal processing, were analyzed focusing in the Albian carbonate oil fields.

With the aim of test the efficiency of sweetness, attributes like Root Mean Square Amplitude (RMS), Instantaneous Frequency, Chaos, Envelope, Main Frequency, First Derivative, Rel- ative Acoustic Impedance, RBG (Red-Blue-Green, three main frequencies are represented by render process), among other were applied on both situations: volumetric and surface attributes analyses. In the case of the test of the surface attributes the interpretation of the at least the reservoir's top is necessary, and sometimes the base is also required to perform the calculus of the seismic attribute.

To apply the extraction of the volumetric attribute, a cropped 


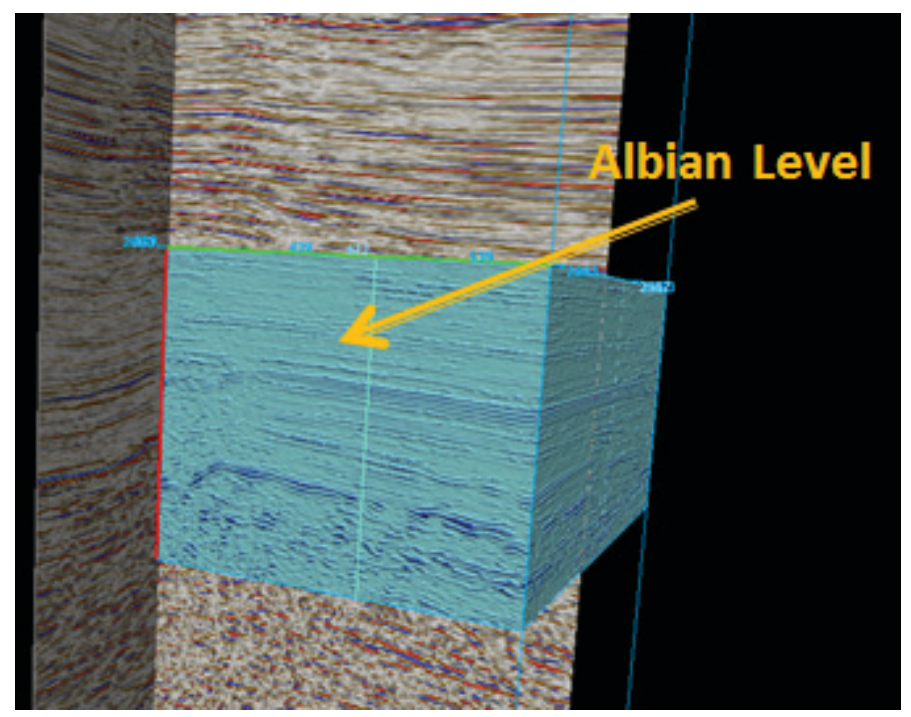

Figure 7 - Sweetness attribute cube (in blue) as a result of the applied algorithm.
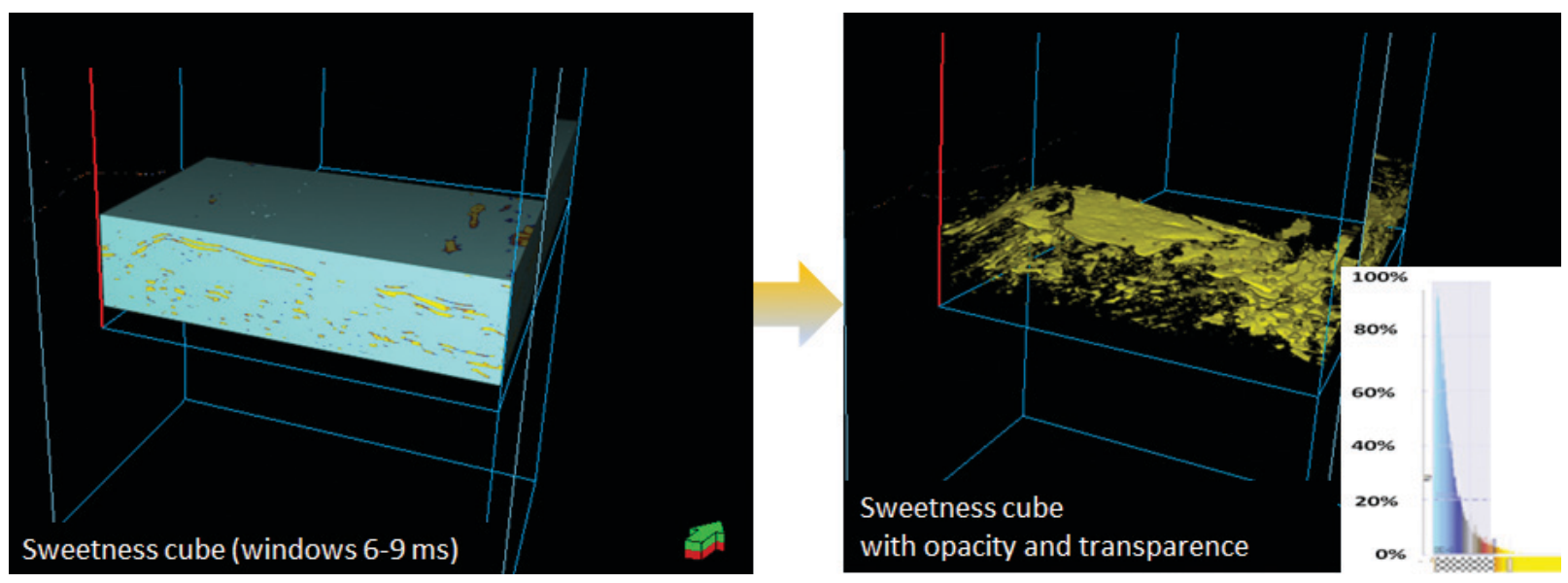

Figure 8 - In the left figure, the sweetness cube is shown. In the right figure, it is possible to observe the main carbonate distribution displaying the lateral discontinuities related to the facies heterogeneities, faults presence or the absence of the carbonatic platform.

volume was created to separate the reservoir interval in order to perform the calculations.

Nevertheless, in order to achieve a high quality on the reservoir visualization, some constrains are recommended to be applied (Fig. 7): the window used in attribute extraction must be ranging between 6 and $9 \mathrm{~ms}$, independent of the seismic sampling interval (2 and $4 \mathrm{~ms}$ were tested).

After performing the volumetric attribute extraction, opacity and transparence techniques of volumetric interpretation were applied over the sweetness cube, resulting in a better discrimination of the main reservoir (Fig. 8). In this sense, for geoscientists that had developed skills to apply opacity and transparency attributes on volumetric seismic interpretation, the process will be a faster way to identify carbonate reservoirs.

\section{RESULTS}

The first comparison between surface and volumetric calculated attributes indicates that it is possible to visualize the reservoir in most of them, mainly when the acoustic impedance (AI) is included on the analysis, nevertheless including the Al some carbonates oil fields do not show any answer on surface attributes, and show a good visualization on volumetric attributes, mainly on sweetness, RMS amplitude, and relative acoustic impedance.

Even when the good visualization is observed on the 3 mentioned volumetric attributes, the best and faster geometrical definition of the reservoir was obtained using sweetness, because it does not require previous seismic interpretation, and the opacity and transparence process performed by the seismic interpreter is 
very well guided by the first result of the attribute (it is like and intuitive process).

The results were divided by the location of the target based on the water depth: shallow less than 200 m, deep between 200 and 1200 meters and ultra-deep more than $1800 \mathrm{~m}$.

The best result was obtained for shallow carbonates reservoirs. When observing the interpreted reservoir in the seismic line (Fig. 9), is difficult to verify the connections of the effective reservoir but, when this visualization is performed on a sweetness attribute, the effective reservoir section is clear (Fig. 10). Observe that the strong reflectors at the upper part of the section are not highlighted by the sweetness. This happens because those levels are not carbonate reservoirs.

The result is better in a 3D visualization. Figure 11 shows the extracted body of the main carbonate reservoir in yellow and its lateral discontinuities, sometimes related to the presence of faults which represent the limits of the carbonate bank.

This feature was tested by wells and compared with calculated

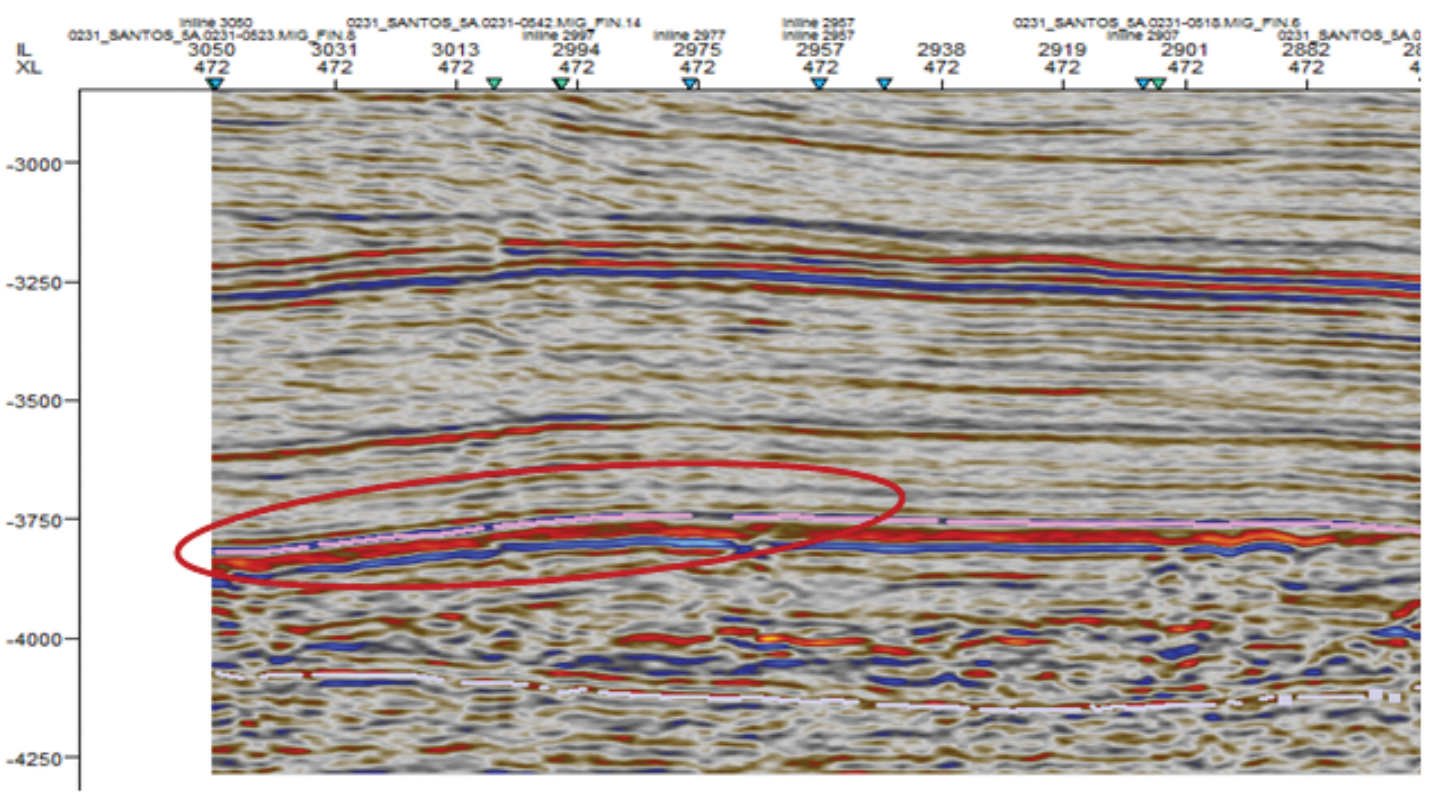

Figure 9 - Seismic line showing the main carbonate reservoir in shallow water depth.

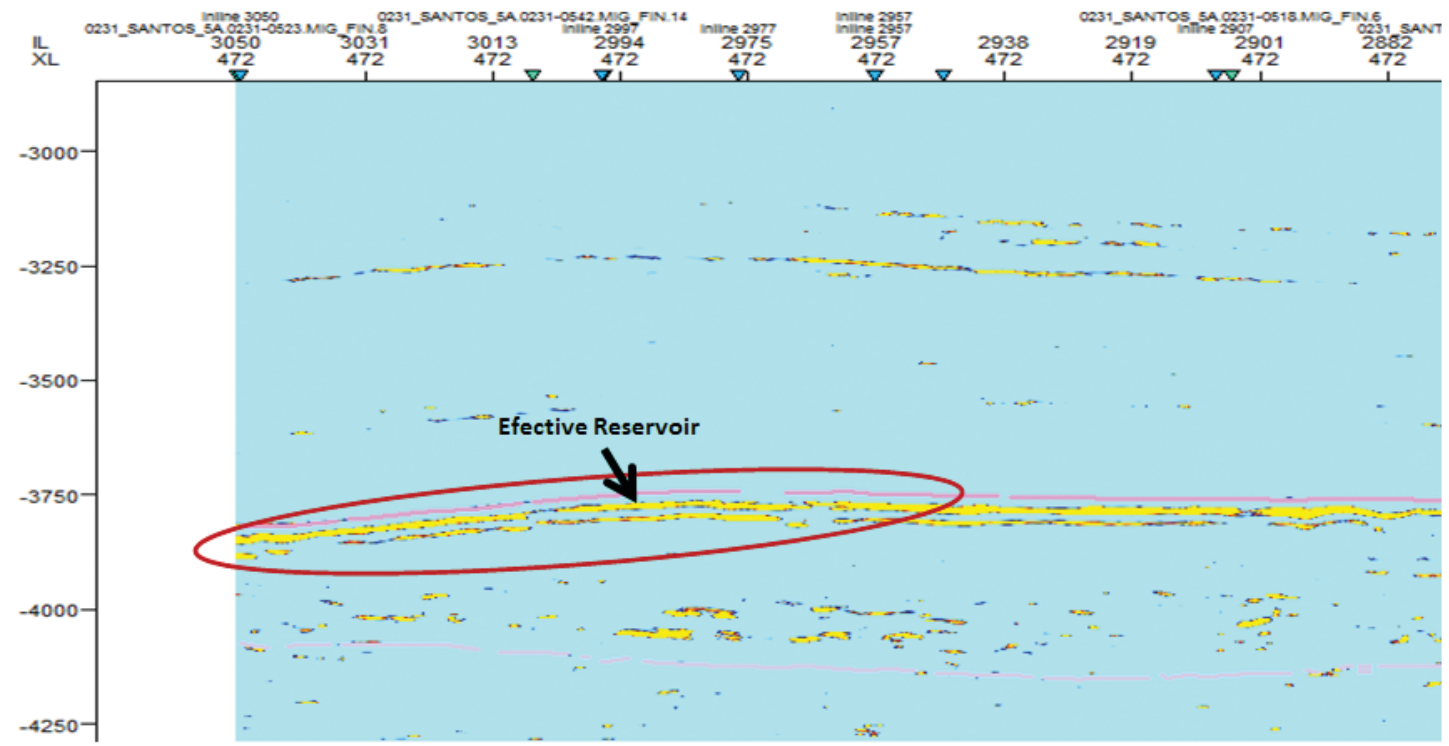

Figure 10 - Sweetness section showing the main carbonate reservoir in shallow water depth. 


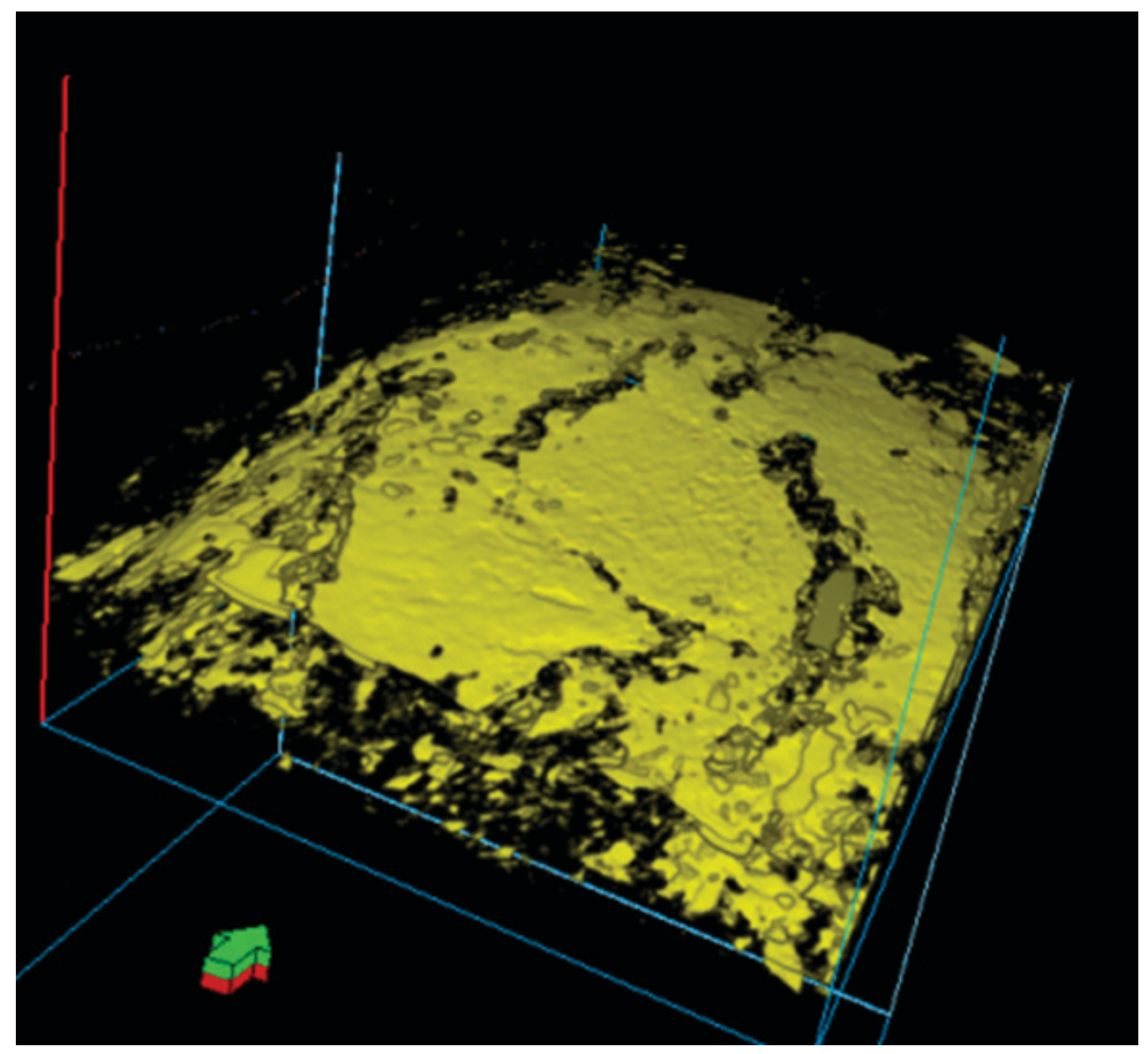

Figure 11 - Carbonate reservoir distribution obtained from the sweetness attribute extraction method.

surface attributes that exhibit a similar reservoir geometry (reservoir shape).

In the intermediate water depth (more than $800 \mathrm{~m}$ ) the main reservoir was clearly visualized as well. However, its resolution was poor (Fig. 12) due to the quality of the seismic surveys available to perform the test and the absence of significant oil fields in the LISG database. Over this data, a high volume of nongeological discontinuities were observed, easily identified.

It is considered by the authors that the poor result on the intermediate water depths is related to the available seismic data to perform this test, because on these seismic volumes there are not oil fields on Albian carbonates. As consequence, the water depth is not important on the analysis.

The extraction in ultra-deep water depth (more than $1800 \mathrm{~m}$ ) is similar to the first situation (shallow), and the same good resolution response was obtained (see Fig. 13).

In summary, the carbonate reservoir attribute extraction method can be applied on any water depth and it shows a very good response for the Albian Brazilian carbonates. The au- thors suggest that this methodology is applicable in any carbonate reservoir, showing how efficient the method can be for any condition of this kind of reservoir, with or without expressive porosities.

\section{CONCLUSIONS}

Volumetric seismic attributes are useful for limestones reservoir characterization.

The sweetness attribute allowed us to interpret a carbonate reservoir in a short period of time, showing how the interpreted reservoir's geometry would be close to the real geometry (less geometrical uncertainty).

The geophysical uncertainty, related to seismic interpretation, is lower when volumetric interpretations of seismic volumetric attributes are applied.

The method is applicable for the seismic characterization of any geological feature that shows changes in the rock density over the surrounding rocks. 


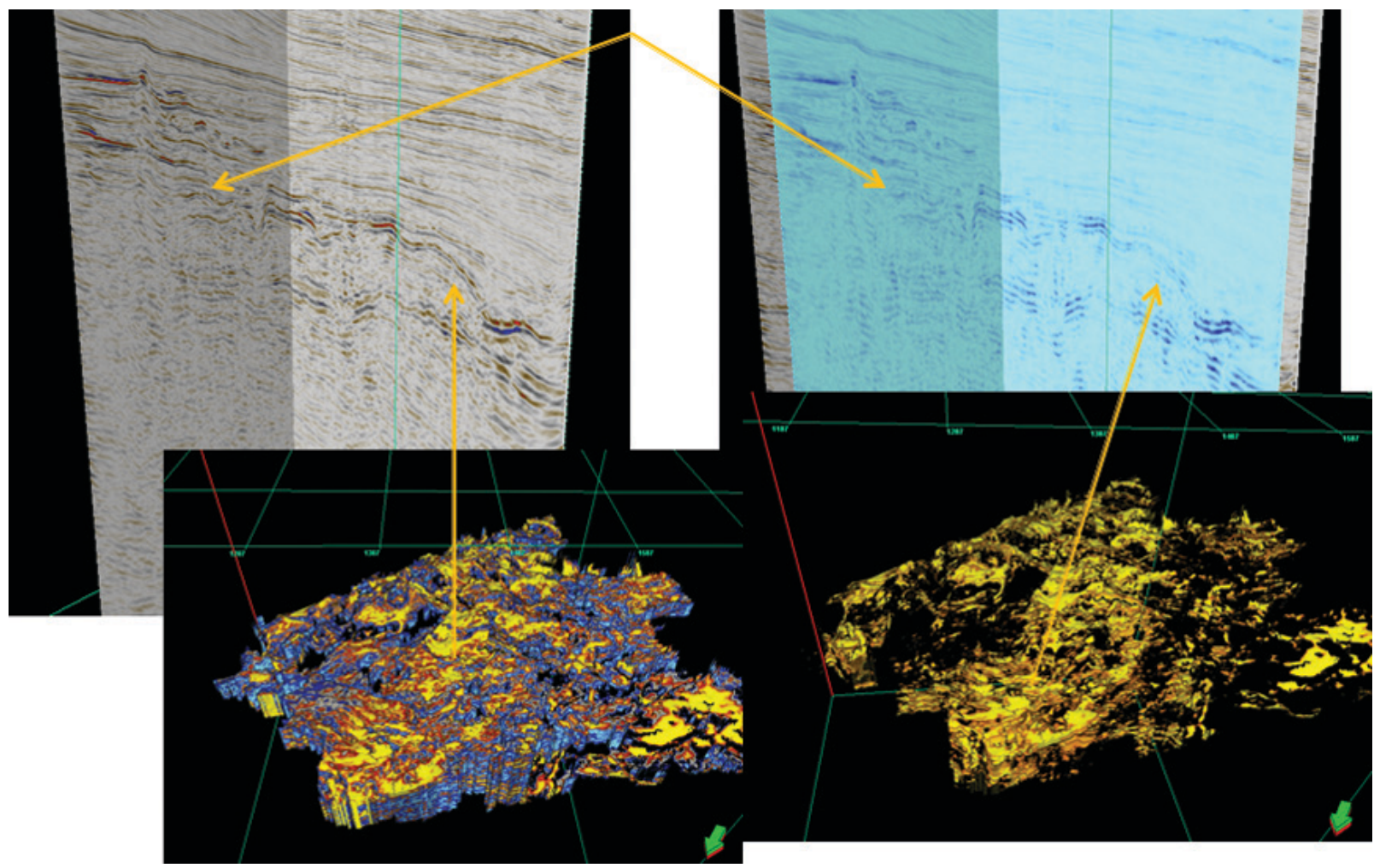

Figure 12 - In the intermediate water depth, it was possible to visualize the main carbonate reservoir. However, the available seismic data did not contain a good resolution. As a consequence, some not geological structures - caused by acquisition and processing noises - and discontinuities are observed.
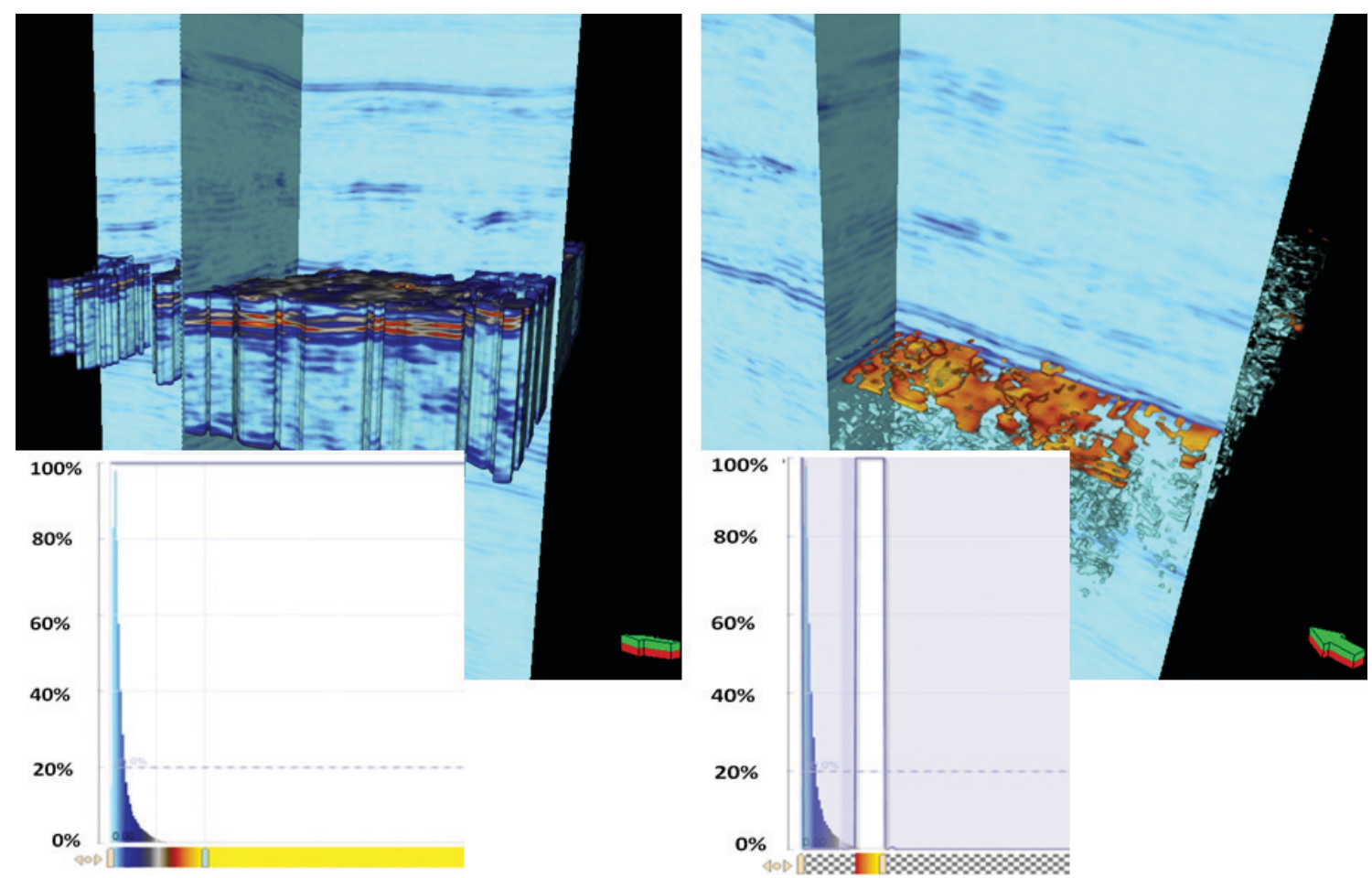

Figure 13 - In the left image, the sweetness attribute extraction is showed with full signal visualization. At the right, observe the distribution of the main carbonate reservoir in yellow after the application of opacity and transparence attributes. 


\section{REFERENCES}

HART B. 2008. Channel detection in 3-D seismic data using sweetness. American Association of Petroleum Geologists Bulletin, AAPG, 92(6): 733-742.
VAIL PR, MITCHUM RM \& THOMPSON III S. 1977. Seismic stratigraphy and global changes of sea level. Part 4: Global Cycles of Relative Changes of Sea Level. American Association of Petroleum Geologists, Memoir, 26: 83-97.

Recebido em 27 setembro, 2013 / Aceito em 8 setembro, 2014

Received on September 27, 2013 / Accepted on September 8, 2014

\section{NOTES ABOUT THE AUTHORS}

Maria Gabriela Castillo Vincentelli is a Senior Geophysicists. Nowadays, is working joint a UNESP-Petrobras partnership at UNESPetro (Center for Petroleum Geoscience), focused on: quantification of rock answer from geophysical data, better practices to define geological facies from seismic facies, seismic inversion, and geological modeling. Has been working on petroleum exploration since 1995, and the last five years also worked on petroleum reservoirs. Graduated as a geophysics engineer by the Central University of Venezuela (1997), where concluded master degree on structural geology (2004). Doctorate was gotten at the UNESP in Regional Geology (2008).

Sergio Antonio Caceres Contreras is a Senior Geophysicists with more than twelve years of experience on basin and velocity modeling; stratigraphic and petrophysical analysis; among others. Currently, is working joint a UNESP-Petrobras partnership at UNESPetro, with the focus of quantify the geophysical answer of the carbonate reservoir in terms of heterogeneities, based on seismic, velocity, density, and neutron data; and its relationship with plug petrophysics, and inversion anomalies distribution. Ph.D. on Regional Geology by the UNESP - Brazil (2008), and got graduate degree at the Central University of Venezuela in 2002 as a geophysics engineer.

Michelle Uchoa Chaves is a Senior Geologist currently working at Schlumberger. Has a Bachelors degree in Geology from State University of Rio de Janeiro (2005), and a Master degree in Geology from Federal University of Rio de Janeiro (2013). From 2006 to 2009 collaborated with Petrobras on 42 different projects, assisting Geoscientists within the Production and Exploration teams. In 2010 joined the Brazil Technology Center to test the features developed for Seismic Well Tie module in Petrel. In 2013 was transferred to the Technology Center in Norway, leading the integration of 2 major applications: Petrel and GeoX. 